\section{The righting reflex in turtles: A description and comparison*}

\author{
VICTOR M. ASHE \\ University of Texas at Arlington, Arlington, Tex. 76010
}

Sixty-three turtles, representing 50 species, were tested for the righting reflex under two conditions, inversion and suspension. Ninety-two percent performed the righting reflex under inversion; $67 \%$ performed the righting reflex under suspension. Differences in the performance of the righting reflex were noted and discussed in terms of natural selection and the evolutionary relationships between the species sampled.

An inverted turtle struggles to regain the upright orientation by extending its limbs and head dorsally toward the surface upon which it rests. When the head or a limb gains purchase on the surface, pressure is applied until the turtle tips himself rightside up. This, generally, describes the righting behavior of turtles. This behavior is, perhaps, a reflexive taxis, in the sense of Frankel \& Gunn (1961); The stimulus situation arising as a consequence of inversion elicits the righting reflex (RR). A search of the recent literature revealed no systematic investigations of the inversion-induced righting reflex. Neither is there a description of suspension-induced righting reflexes. An instance of suspension-induced $R R$ was noted in a photograph, in which a turtle was suspended with its plastron (ventral shell) at rest atop a glass vessel with all four limbs free from physical contact. This pose is often employed by herpetologists when photographing turtles.

The present study undertakes (1) to establish the existence of the righting reflex, induced by inversion and by suspension, and (2) to provide a comparison across species in the performance of the righting reflex.

\section{SUBJECTS}

The sample observed consisted of 63 members of the herpetile collection of the Dallas Zoo in Dallas, Texas. The sample crossed 8 families, 33 genera, with at least one representative from each of 50 species. Ss ranged in age from adolescent to adult. The Ss were housed either in exhibit aquariums and terrariums or in nonexhibit facilities. Environmental factors remained constant throughout the study, and the feeding and cleaning routine of the herpetarium was not interrupted. Room temperature was maintained at $27^{\circ} \mathrm{C}$ with the exception of the amphibian room, which was maintained at $22^{\circ}-23^{\circ} \mathrm{C}$. Consult Table 1 for a list of Ss.

*The author is indebted to the staff of the Dallas Zoo Herpetarium without whose cooperation the study would not have been possible.

\section{PROCEDURE}

Each $S$ underwent two manipulations, and the ensuing behavior was recorded. The first manipulation consisted of inverting the $S$ on its carapace. After the $S$ responded, or after the lapse of $30 \mathrm{~min}$, the second manipulation was initiated. This consisted of suspending $S$ with its weight concentrated on its plastron and with all four limbs free from any stimulation arising from mechanical contact. Suspension was accomplished in one of two ways: medium to large Ss were placed atop a glass vessel, smaller $S$ s were placed atop a dowel rod of sufficient diameter to adequately support the $S$.

Inversion-Induced

Righting Reflex (RR-I)

Fifty-eight of the 63 Ss performed the righting reflex following inversion. Some differences and exceptions were noted and are described under the following headings. The letter designations provide a cross-reference between the Results text and Table 1. These designations indicate deviations from the "generalized" RR. The generalized $R R$ is arbitrarily described thus: The $S$ gradually extends the neck and limbs; then the head and feet are extended or thrust dorsally, a maneuver that usually enables the $S$ to gain purchase on the surface upon which it rests; when contact is made, the $S$ pushes against the surface and tips itself right-side up.

(A) Short latency. All nine Terrepenes made the RR immediately following inversion. This contrasts with other Ss whose latency ranged up to $30 \mathrm{~min}$.

(B) Ventral orientation of the head. Curora amboinensis and Testudo hermani exhibited this behavior. $C$. amboinensis subsequently thrust its head dorsally, whereas $T$. hermani persisted with head and tail ventrally oriented.

(C) Pivoting. Testudo graeca graeca and Pelusios gabonensis moved their limbs in such a way that, had these Ss been upright, they would have pivoted on a poiıt. One lateral pair of limbs were moved as in forward locomotion, while the other lateral
RESULTS pair were moved in the opposite direction. After a brief interval this behavior was resumed. but each limb pair reversed direction.

(D) Horizontal head bobbing. Geochelone elegans bobbed its head and kicked vigorously. The kicking was not synchronous and the limbs were oriented ventrally. Geochelone elegans radiata exhibited similar behavior, but moved much more rapidly. Geochelone pardalis babcocki bobbed its head and kicked the uppermost lateral limb pair synchronously (one lateral limb pair is uppermost because the carapace is not flat; thus. when resting on its carapace, the turtle tilts to one side).

(E) Use of prehensile tail in the righting reflex. Platysternon m. megacephalum used its strong tail as well as its head to push against the surface upon which it rested to right itself.

(F) No inversion-induced righting reflex. Six Ss did not respond to inversion with the righting response. The two members of the species Seibenrockiella crassicollis were recent additions to the collection. One Pseudemy's scripta elegans, one Chelydras. serpentina, one Nachrochelys temmincki, and one Platemys platycephalia were housed in nonexhibit facilities and perhaps had not yet become accustomed to humans. This tentative explanation is supported by the performance of the righting reflex by another Pseudemys scripta elegans and another Chelydras. serpentina.

\section{Suspension-Induced}

Righting Reflex (RR-S)

Forty-two of the 63 Ss exhibited the righting reflex in response to suspension. The observed differences may be conveniently described under the following categories (also refer to Table 1).

(G) Short latency. All the Terrepenes were extremely rapid in responding to this manipulation with the righting reflex.

(H) Reconnaissance. Characteristically, Ss attentively moved their heads horizontally and vertically; Ss visually tracked moving objects. The Ss exhibiting this reconnaissance behavior were Batrachemys nasuta, Platystemon $m$. megacephalum, and Geoclemys hamiltoni.

(I) Partial righting reflex. Emys blandingi, Geochelone elongata, Gopherus berlandieri, and Malacochersus tornieri moved forelimbs dorsally but did not elevate head dorsally.

(J) Swimming reflex. Trionyx spinifer emoryi and Lissemys $p$. granosa did not perform the righting reflex in response to suspension. However, these Ss moved their limbs in a coordinated fashion closely resembling swimming. The $\mathrm{E}$ was able to observe these Ss in their home tank and 
Table 1

Taxonomy of Ss. Results of the Two Manipulations, and the Observed Deviations from the Generalized Righting Reflex Behavioral Deviations

lamily

Kinosternidas

Chelydridae

Platysternidae Testudinidae

Lmydidat

Trionychidae

Chelidae

Pelomedusidae
Kinosternon tlavestens Kinosternons. hippocrepis

Kinosternon sonoriense

Kinosternon s. subrubrum

Stau roty pus triporcatus

Sternotherus odoratus

Chelydra s. serpentina,

Chelydra s. serpentinal

Macrochelys temmincki

Platysternon m. megacephalum

Geochelone eleuani2

Geochelone elegans radiata ${ }^{3}$

Geochelone elongata ${ }^{4}$

Geochelone pardalis babcocki ${ }^{5}$

Gopherus agassiz ${ }^{6}$

Gopherus berlandieri

Gopherus berlandieri

Malacochersus tornieri ${ }^{7}$

Testudo g. graeca

Testudo hermani

Clemmys caspicia leoprosa ${ }^{8}$

Clemmis guttata

Chinemys reevesii

Chrysemy's picta belli

Chry semys picta picta

Curora amboinensis

Deirochely's reticularia

Emys blandingi ${ }^{7}$

Emys obicularis

Geoclemys hamiltoni

Gromyda pulcherrima

Graptemys barbouri

Graptemss kohni

Graptemys kohni

Graptemys versa

Graptemys versa

Valaclemys terrapin littoralis

Pseudenus concinna floridana

Pseudemys concinna texana

Pseudemys scripta elegans

Pseudemys scripta elegans

Seibenrockiella crassicollis

Terrapene carolina carolina

Terrapene carolina carolina

Terrapene carolina carolina

Terrapene carolina triunguis

Terrapene carolina triunguis

Terrapene carolina triunguis

Terrapene 0 . ornata

Terrapene o. ornata

Terrapene o. ornata

Lissemys p. granosa 9

Trionyx spinifera emoryi

Trionv's spinifera emoryi

Trionyx spinifera emoryi

Batrachemys nasuta ${ }^{10}$

Lmydura kreffti

Emidura macquari

Platemys platy cephalia

Prinops ge of froanus

Pelomedusa subrufra

Pelusios gabonensis

Podocnemis unifilis

Results

\begin{tabular}{llllllllllll} 
RR-I RR-S A & $B$ & $C$ & $D$ & $E$ & $F$ & $G$ & $H$ & I & J & $K$ \\
\hline
\end{tabular}

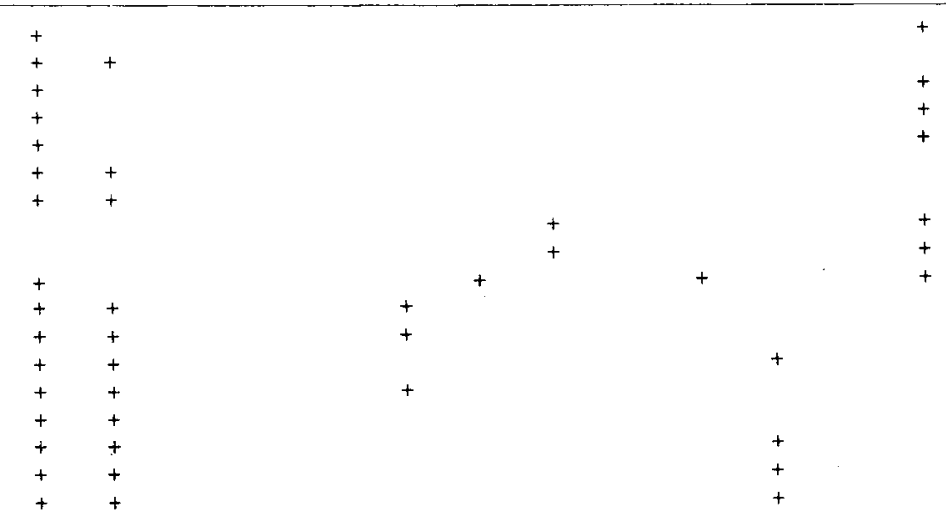


thereby compare the suspension-induced response to actual swimming: the movements were identical.

(K) Vo suspension-induced righting reflex. As noted above, 20 Ss did not respond to suspension with the righting reflex. As with Item $F$, some of these Ss may not have been acclimated to the herpetarium environment. However, 15 of the $20 \mathrm{Ss}$ made other responses including the inversion-induced righting reflex, suggesting that failure to perform the suspension-induced RR is attributable to factors other than preacclimation "shyness." These 15 Ss may be located in the table by noting those entries with both RR-I and K items marked and RR-S blank. DISCUSSION

Within the limits of the sample, it is reasonable to conclude that the $R R$ is included in the behavior repertoire of a variety of turtles. The RR was exhibited by members of all eight of the families sampled.

The difference in the frequency of the inversion-induced $R R$ compared to the suspension-induced RR might be explained in terms of the adaptation (aquatic or terrestrial) of the Ss sampled. Few, if any, species could be described as being totally restricted to one or the other habitat. Thus, it seems appropriate to think of the relative differences in adaptation as loci on a continuum. For example, the large tortoises of the Galapagos Islands would be located toward the extreme of terrestrial adaptation, while the marine turtles would be located toward the other extreme of aquatic adaptation. Many of the Ss in this study fall somewhere between these extreme points.

The relatively low frequency of suspension-induced RR exhtbited by Pelomedusidae ( 1 of $3,33 \%)$, Kinosternidae ( 2 of $6,20 \%$ ), Trionychidae $(0 \%)$, and Chelidae (0\%) suggests that these families are more aquatically adapted than are other families in the sample. It should be noted that these families exhibiting similar responses to the manipulations are widely separated with respect to common ancestral lineage: Though Chelydridae and Kinosternidae have been separated for only 35 million years, they have been separated from Chelidae and Pelomedusidae for over 185 million years and from Trionychidae for about 140 million years (Pritchard, 1967). Moreover, families separated for only 70 million years (Trionychidae vs Testudinidae and Emydidae) are divergent in their responses to suspension: Testudinidae and Emydidae respond to suspension with the RR ( 10 of $10,100 \%$, and 29 of $32,90 \%$, respectively). Perhaps it would be more appropriate to view these results as a function of similar adaptation since aquatic adaptation in turtles is currently regarded as secondary (Pritchard, 1967), and thus could be a parallel development in several different families.

A number of "idiosyncratic" differences in the performance of the RR were noted. Some of these are most certainly adaptive. Geochelone elegans, G. elegans radiata, and $G$. pardalis babcocki had high, steep carapaces (see their respective footnotes in Table 1); thus, when inverted, they are tilted to one side or the other. Their RR consists of vigorous kicking which effectively shifts them $90 \mathrm{deg}$ so that they come to rest on the lateral carapace. In this position the head and legs can reach the surface upon which they rest; the general RR maneuvers then achieve upright orientation. Since the carapace height of these three Ss precludes the success of the generalized RR from the inverted position, the vigorous kicking maneuver is obviously adaptive and probably evolved with the steep carapace. The use of a prehensile tail by Platysternon $m$. megacephalum in the inversion-induced RR is advantageous; this $S$ literally flips itself upright by a coordinated movement of the head and tail. The swimming response elicited by suspension in all three members of the family Trionychidae is an adaptive behavior for an aquatically-adapted turtle that is unlikely to experience extraaquatic suspension in nature. It is tempting to speculate that the suspension condition of this study constitutes a stimulus situation similar to that provided by suspension in water (as in nature) and thus elicits the same response, i.e., swimming. The short latency of the RR to inversion is adaptive for the Terrepenes which would dry up and die in the semiarid expanses of its range if it were to rest inverted for very long. The same would be true of the Testudinidae were they not more specialized for arid and semiarid ranges, though, in fact, these latter have a latency not greater than approximately $10 \mathrm{~min}$. The author is hard put to explain some of the recorded behaviors in terms of adaptation. The selective advantage of ventral orientation of the head and pivoting ( $B$ and $C$, Table 1) is not readily apparent. The inadequate representation of some of the taxons sampled precludes a precise description of species-specific behavior. However, the results do indicate trends that might be fruitfully investigated. All Ss that responded (i.e., that were not "shy") exhibited the RR when inverted. Ss which were relatively more terrestrial exhibited the RR when suspended. The more aquatic turtles tended not to exhibit the RR when suspended, possibly because the stimulus constellation of aquatic suspension and that of experimental suspension are similar. The penis erection exhibited by Batrachemys nasuta during suspension suggests the possibility that the mounting of the female by the male has some stimulus similarity to experimental suspension, or perhaps suspension was stressful and elicited the erection as an emotional response.

\section{REFERENCES}

FRAENKEL, G. S., \& GUNN, D. L. The orientation of animals. New York: Dover. 1961.

PRITCHARD, P. C. H. Living turtles of the world. Jersey City, N.J: T. F. H. Publications, 1967. 